\title{
Modelling cereal crops to assess future climate risk for family food self-sufficiency in southern Mali
}

\author{
Bouba Traore $^{\mathrm{a}, \mathrm{b}, *, 1}$, Katrien Descheemaeker ${ }^{\mathrm{c}}$, Mark T. van Wijk ${ }^{\mathrm{d}}$, Marc Corbeels ${ }^{\mathrm{e}, \mathrm{f}}$, \\ Iwan Supit ${ }^{g}$, Ken E. Giller ${ }^{\mathrm{c}}$ \\ a Institut D'Economie Rurale (IER), Programme Coton, SRA N'Tarla Bp: 28 Koutiala, Mali \\ ${ }^{b}$ International Crops Research Institute for the Semi-Arid Tropics (ICRISAT-Mali), BP 320 Bamako, Mali \\ c Plant Production Systems, Wageningen University, P.O. Box 430, 6700 AK Wageningen, The Netherlands \\ ${ }^{\mathrm{d}}$ Livestock Systems and the Environment, International Livestock Research Institute (ILRI), P.O. Box 30709, 00100 Nairobi, Kenya \\ e Agro-ecology and Sustainable Intensification of Annual Crops, Centre de Coopération Internationale en Recherche Agronomique pour le Développement \\ (CIRAD)-Av. Agropolis, 34060 Montpellier, France \\ ${ }^{\mathrm{f}}$ Sustainable Intensification Program, International Maize and Wheat Improvement Center (CIMMYT), P.0. Box 1041-00621, Gigiri, Nairobi, Kenya \\ ${ }^{g}$ Earth System Science and Climate Adaptive Land Management, Wageningen University and Research, P.O. Box 47, 6700 AK Wageningen, The Netherlands
}

\section{A R T I C L E I N F O}

\section{Article history:}

Received 29 April 2016

Received in revised form 7 November 2016

Accepted 11 November 2016

\section{Keywords:}

Crop simulation modelling

Planting date

Fertilizer use

APSIM

Sub-Saharan Africa

Climate change

\begin{abstract}
A B S T R A C T
Future climate change will have far reaching consequences for smallholder farmers in sub-Saharan Africa, the majority of whom depend on agriculture for their livelihoods. Here we assessed the farm-level impact of climate change on family food self-sufficiency and evaluated potential adaptation options of crop management. Using three years of experimental data on maize and millet from an area in southern Mali representing the Sudano-Sahelian zone of West Africa we calibrated and tested the Agricultural Production Systems sIMulator (APSIM) model. Changes in future rainfall, maximum and minimum temperature and their simulated effects on maize and millet yield were analysed for climate change predictions of five Global Circulation Models (GCMs) for the $4.5 \mathrm{Wm}^{-2}$ and $8.5 \mathrm{Wm}^{-2}$ radiative forcing scenario (rcp4.5 and rcp8.5).

In southern Mali, annual maximum and minimum temperatures will increase by $2.9^{\circ} \mathrm{C}$ and $3.3^{\circ} \mathrm{C}$ by the mid-century (2040-2069) as compared with the baseline (1980-2009) under the rcp4.5 and rcp8.5 scenario respectively. Predicted changes in the total seasonal rainfall differed between the GCMs, but on average, seasonal rainfall was predicted not to change. By mid-century maize grain yields were predicted to decrease by $51 \%$ and $57 \%$ under current farmer's fertilizer practices in the rcp 4.5 and rcp 8.5 scenarios respectively. APSIM model predictions indicated that the use of mineral fertilizer at recommended rates cannot fully offset the impact of climate change but can buffer the losses in maize yield up to $46 \%$ and $51 \%$ of the baseline yield. Millet yield losses were predicted to be less severe under current farmer's fertilizer practices by mid-century i.e. $7 \%$ and $12 \%$ in the rcp 4.5 and rcp 8.5 scenario respectively. Use of mineral fertilizer on millet can offset the predicted yield losses resulting in yield increases under both emission scenarios.

Under future climate and current cropping practices, food availability is expected to reduce for all farm types in southern Mali. However, large and medium-sized farms can still achieve food self-sufficiency if early planting and recommended rates of fertilizer are applied. Small farms, which are already food insecure, will experience a further decrease in food self-sufficiency, with adaptive measures of early planting and fertilizer use unable to help them achieve food self-sufficiency. By taking into account the diversity in farm households that is typical for the region, we illustrated that crop management strategies must be tailored to the capacity and resource endowment of local farmers. Our place-based findings can support decision making by extension and development agents and policy makers in the Sudano-Sahelian zone of West Africa.
\end{abstract}

(C) 2016 Elsevier B.V. All rights reserved.

\footnotetext{
* Corresponding author at: Institut D’Economie Rurale (IER), Programme Coton, SRA N'Tarla Bp: 28 Koutiala, Mali.

E-mail addresses: boubasiditraore@yahoo.fr, B.Traore@cgiar.org (B. Traore).

1 Current address: International Crops Research Institute for the Semi-Arid Tropics (ICRISAT-Mali), BP 320 Bamako, Mali. 


\section{Introduction}

Climate change will adversely affect food production in many regions of the world, especially in sub-Saharan Africa where a large part of the population faces chronic hunger (Lobell et al., 2008). The observed changes in rainfall and temperature since the $1970 \mathrm{~s}$ are believed to have resulted in a decline of overall crop production (Barrios et al., 2008). Climate change projections for the West African region indicate a further increase in temperature of between 1.1 and $4.8^{\circ} \mathrm{C}$ and larger differences in rainfall between wet and dry seasons at the end of this century (IPCC, 2013).

A review of climate change impact studies on crop yields in West Africa illustrates a large dispersion of crop yield changes ranging from $-50 \%$ to $+90 \%$, with a median yield loss of about $11 \%$ (Roudier et al., 2011). Predicted impact is larger in Sudano-Sahelian countries, with an average yield loss of $18 \%$, compared with the countries in the Southern Guinea Savannah zone where the predicted yield loss is $13 \%$ (Sultan et al., 2013). This difference is likely due to the already drier and warmer climate in the more northerly countries of West Africa. In the short term, (2010-2040), crop yields at the Malian national level are predicted to vary between $-17 \%$ and $+6 \%$ of the current yields (Butt et al., 2005a). It is believed that the negative impact of climate change mainly results from effects of rising temperature, which is predicted with a stronger signal and less uncertainty compared to precipitation changes (Roudier et al., 2011). Schlenker and Lobell (2010) showed that even if rainfall remained constant in sub-Saharan Africa by mid-century, crop yields would decrease by about $15 \%$ due to the higher temperatures reducing the length of the crop growth cycle and increasing water stress as a result of greater soil water evaporation losses.

New evidence of climate change (IPCC, 2013) highlights the need to adapt cropping systems. For Mali, Butt et al. (2005b) argued that by implementing adaptive responses such as the use of hightemperature-resistant crop varieties together with addressing soil fertility decline, economic gains could exceed losses due to climate change. Various adaptation options that Malian farmers currently practice to cope with climate variability could be considered. In general, these are tactical adaptations of farm management (such as shifting to crop landraces, altering fertilization), but also include more strategic adaptations of altered income/asset management (Chuku and Okoye, 2009). A common operational adaptation to address climate risk in semi-arid and sub-humid regions is to shift the planting date to coincide with the altered start of the rainy season (Muller et al., 2010).

Linking climate change scenarios with crop simulation modelling to assess the response of crop production to climate change in combination with adaptive farm management, provides information that can enhance strategic decision-making by farmers and policy makers to adapt to the novel challenges of a changed climate (Rosenzweig et al., 2013). The few regional impact studies that have taken into account adaptation options by farmers (Fraser et al., 2011) are difficult to translate into knowledge that can drive local solutions. Local studies with crop models are generally better suited to support locally appropriate decision-making than regional approaches (Fischer et al., 2005). Yet few of such locally-relevant studies exist in sub-Saharan Africa (Tingem et al., 2009; Sultan et al., 2013). One crop simulation study in Cameroon showed that altering planting date and cultivar type can reduce the negative impacts of climate change and even increase crop yields (Tingem and Rivington, 2009). As farms in sub-Saharan Africa are very diverse (Giller et al., 2011), the impact of climate change and the feasibility of adaptation options are likely to differ among farmers. However, with climate change impact studies usually focussing solely at the field scale, farm-level information that is disaggregated by farm type is scarce. Thus, more locally grounded research on likely crop responses to climate change and effects on farm-level indicators are needed to support decision-making on adaptation strategies to mitigate negative impacts of changing climate.

This study aimed to better understand future climate change, its impact on cereal crop production, and the potential of adaptation options in southern Mali. Our specific objectives were: (i) to calibrate and test the crop model APSIM (Agricultural Production Systems sIMulator) for maize and millet in Sudano-Sahelian conditions; (ii) to analyse changes in future rainfall, maximum and minimum temperature under two emission scenarios leading to a radiative forcing of $4.5 \mathrm{Wm}^{-2}$ and $8.5 \mathrm{Wm}^{-2}$ by mid-century (2040-69); (iii) to assess the impact of climate change on yields of maize and millet; (iv) to evaluate potential adaptation options of crop management and ( $v$ ) to quantify the farm-level consequences for food self-sufficiency of different types of smallholder farmers in southern Mali.

\section{Materials and methods}

\subsection{Site}

We examined the effects of future climate on cereal crop production at N'Tarla $\left(12^{\circ} 35^{\prime} \mathrm{N}, 5^{\circ} 42^{\prime} \mathrm{W}, 302 \mathrm{~m}\right.$ a.s.l.). N'Tarla is representative of the cereal crop production region in Mali and occupies $14 \%$ of the territory. This region holds about $40 \%$ of the total population and 50\% of the cultivable land of Mali (Deveze, 2006). The climate in southern Mali is typical of the SudanoSahelian zone of West Africa. Average long-term annual rainfall at N'Tarla is $846 \pm 163 \mathrm{~mm}$. The rainy season extends from May to October with an average temperature of $29^{\circ} \mathrm{C}$. Farming systems in the region are mixed agro-pastoral systems, with cotton (Gossypium hirsutum L.) as the main cash crop, in rotation with cereals - maize (Zea mays L.), pearl millet (Pennisetum glaucum (L.) R.Br.), sorghum (Sorghum bicolor(L.) Moench), - and legumes - groundnut (Arachis hypogaea L.) and cowpea (Vigna unguiculata (L.) Walp.).

\subsection{Experimental data for model calibration and testing}

We used data on maize and millet from a field experiment conducted over three consecutive growing seasons from 2009 to 2011 at N'Tarla. The experiment was a split-split-plot design with three factors (crop, variety, planting date) and four replicates. The main plot treatment was the crop (maize, pearl millet). On the sub-plots three varieties were tested, referred to as V1 and V2 for long duration variety and V3 for short duration variety (Table A1) and three planting dates covered the possible range of planting dates in southern Mali, referred to as D1 (early planting date), D2 (medium planting date) and D3 (late planting date). Each year, all plots received three tonnes dry matter per hectare of manure (with an organic matter content of $44 \%$ and $\mathrm{C} / \mathrm{N}$ ratio of 12 and organic carbon content of $22 \%$ ) and crop-specific recommended fertilizer doses (IER/CMDT/OHVN, 1998). Maize received $85 \mathrm{~kg} \mathrm{~N} \mathrm{ha}^{-1}$, $26 \mathrm{~kg} \mathrm{Pha}^{-1}$ and $16 \mathrm{~kg} \mathrm{Kha}^{-1}$, whilst millet received $39 \mathrm{~kg} \mathrm{Nha}^{-1}$ and the same amounts of $\mathrm{P}$ and $\mathrm{K}$ as maize. The soil of the experimental site is a Ferric Lixisol (FAO soil classification) with 4\% clay, $16 \%$ silt and $80 \%$ sand content in the $0-40 \mathrm{~cm}$ soil layer. The soil is slightly acid with a pH of 5.6. Organic carbon content is $2 \mathrm{~g} \mathrm{~kg}^{-1}$ soil $(0-40 \mathrm{~cm})$.

For each variety of maize and millet, phenological development was monitored and the dates of emergence, end of juvenile phase, floral initiation, flag leaf stage, flowering, start of grain filling and physiological maturity were recorded. Leaf area index (LAI) of maize and millet plants was measured at 15, 30, 45, 60 and 75 days after planting. Crops were harvested after physiological maturity and stover and grain dry matter yields were determined. The experiment was described in detail by Traore et al. (2014). 
Daily rainfall, minimum and maximum temperature and radiation were recorded at the N'Tarla meteorological station situated at about $1 \mathrm{~km}$ from the experimental field.

\subsection{Model simulations}

The APSIM (Agricultural Production Systems sIMulator) model (Keating et al., 2003) in combination with climate model output of the Coupled Model Intercomparison Project Phase 5 (CMIP5) (Taylor et al., 2012) was used to assess climate change impacts on maize and millet yields, and to evaluate altered planting dates and fertilisation as adaptation options to climate change (see below, Section 2.5). The APSIM Maize (7.4) and the APSIM Millet (7.4) modules together with the soil water module (SoilWat) and the soil nitrogen module (SoilN) of APSIM were parameterized and tested using the results of the above described experiment. In this way, we simulated the growth of maize and millet as limited by soil water and nitrogen.

\subsubsection{Model parameterization}

The values for crop and soil parameters in APSIM were measured at the experimental site, derived from literature or obtained by calibrating the model using crop development and growth data of one year (2010) of the experiment (Tables 1 and 2). Values for phenological parameters for the different maize and millet varieties were based on calculated thermal time between observed phenological development stages of the crops (Table 1). Base temperature, maximum grain number per head and grain growth rate were calibrated based on observed biomass and grain production data of 2010. For the coefficients of the regression function describing the relation between the area of the largest leaf of millet and the total number leaves, published values were used (Akponikpè et al., 2010).

Soil water content at the drained upper limit $(D U L)$, at the lower limit $(L L)$, and at saturation (SAT) were based on measurements performed at the experimental site (Table 2). The bare soil runoff curve number was set at 40 to account for low runoff due to the flat topography of the experimental site and the soil water characteristics of a sandy soil. Soil organic carbon, soil pH and soil bulk density were measured at the experimental site. Initial soil conditions for water and soil mineral $\mathrm{N}$ content were set using observed data from the experiment in 2010, both for the calibration and validation runs. Observed soil water contents measured with a neutron probe at a week before planting date were $16 \mathrm{~mm}, 19 \mathrm{~mm}, 21 \mathrm{~mm}, 21 \mathrm{~mm}$, $43 \mathrm{~mm}$, and $42 \mathrm{~mm}$ in the $0-0.1 \mathrm{~m}, 0.1-0.2 \mathrm{~m}, 0.2-0.3 \mathrm{~m}, 0.3-0.4 \mathrm{~m}$, $0.4-0.6 \mathrm{~m}$ and $0.6-0.8 \mathrm{~m}$ soil layers, respectively. Initial values for mineral $\mathrm{N}(0-0.8 \mathrm{~m})$ were $31 \mathrm{~kg} \mathrm{ha}^{-1}$ for $\mathrm{NO}^{-}{ }_{3}$ and $14 \mathrm{~kg} \mathrm{ha}^{-1}$ for $\mathrm{NH}^{+}{ }_{4}$.

\subsubsection{Model evaluation}

The model was tested against data of the total aboveground biomass, grain yield and LAI measured in 2009 and 2011. Model performance was evaluated graphically and quantified by calculating the root mean squared error (RMSE), with lower values indicating better model agreement with observed values, the $R^{2}$ of the regression between observed and simulated values, ranging from 0 to 1 , with higher values expressing a better linear relationship, and the model efficiency (EF) (Willmott et al., 1985), ranging from $-\infty$ to 1 with higher values indicating a better agreement between observed and simulated values:

$R M S E=\sqrt{\frac{\sum_{i=1}^{n}(O i-P i)^{2}}{n}}$
$E F=\frac{\sum_{i=1}^{n}(O i-\bar{O})^{2}-\sum_{i=1}^{n}(P i-\bar{O})^{2}}{\sum_{i=1}^{n}(O i-\bar{O})^{2}}$

where $O_{i}$ and $P_{i}$ are the observed and simulated values, $\bar{O}$ is the mean of the observed values and $n$ is the number of observations.

\subsection{Climate scenarios}

We used the latest CMIP5 climate modelling results for the historical (1976-2005) and future climate scenarios. Two greenhouse gas emission scenarios were considered as described in the special report on emission scenarios (Nakicenovic et al., 2000). Under a high Representative Concentration Pathway (RCP8.5), the atmospheric $\mathrm{CO}_{2}$ concentration will rise to $850 \mathrm{ppm}$ by the end of the century and annual mean temperature in Africa will increase by 3 to $6{ }^{\circ} \mathrm{C}$ (IPCC, 2014). In the rcp4.5 scenario the atmospheric $\mathrm{CO}_{2}$ concentration will stabilize at $550 \mathrm{ppm}$ and temperature in Africa will increase by 2 to $5{ }^{\circ} \mathrm{C}$ (IPCC, 2014). We did not account for $\mathrm{CO}_{2}$ fertilization effects in the simulations and assumed that maize and millet as $\mathrm{C} 4$ plants benefit relatively little from increased $\mathrm{CO}_{2}$ concentrations (Taylor et al., 2014). It has been shown that impacts of increased temperatures coupled with soil moisture changes will largely override the compensating effects of increased $\mathrm{CO}_{2}$ on crop yields (Rosenzweig and Parry, 1994).

\subsection{Analysis of climate change, its impacts on crop yield and effects of adaptation options}

In order to span some of the uncertainty in climate projections, climate data of five Global Circulation Models (GCMs) (cnrm-cm5, ecearth, hadgem2-es, ipsl-cm5a-lr, mpi-esm-lr) were used. The particular GCMs were selected firstly because they belong to the list of CMIP5 (Coupled Model Intercomparison Project) models (Taylor et al., 2012) and secondly because daily bias-corrected data for maximum and minimum temperature and rainfall were readily available on a $0.5 \times 0.5^{\circ}$ grid for the study site over the period 1976 to 2005 for the past climate and over the 2006 to 2099 period for future climate. Radiation data was bias-corrected according to the method of Haddeland et al. (2012). The method of Piani et al. (2010) was used to bias-correct temperature and rainfall. For both methods the WATCH forcing data was used as a baseline (Weedon et al., 2011).

Future minimum and maximum temperature and rainfall were compared with the baseline conditions by means of graphical analyses showing monthly averages and ranges of the selected climate indicators for the growing season (from the beginning of May to the end of October). We compared each GCM in order to understand the uncertainty in the climate data and used analysis of variance (ANOVA) to test for significant differences between GCMs. For the analysis of the impacts of climate change on crop production we used simulated climate data from the individual GCMs and subdivided the entire simulation period so as to have continuous series of 30 years for baseline (1980 to 2009), and near (2010 to 2039), mid (2040 to 2069) and end (2070 to 2099) of the century periods. Because of increase of uncertainty in predicted climate data towards the end of century, we focused our crop model analysis on the mid-century period. The crop yields predicted with climate data from the five GCMs were compared in order to understand the uncertainty in the yield predictions related to the uncertainty in the predicted climate data.

We first analysed the effects of climate change under the two emission scenarios (rcp4.5 and rcp8.5) on crop yield for the long (V1) and the short duration (V3) varieties of maize and millet with early planting date (D1) and under current farmer's fertilization 
Table 1

Crop parameters for the long (V1, V2) and short (V3) duration varieties of maize and millet used in the APSIM simulations.

\begin{tabular}{|c|c|c|c|c|c|c|}
\hline & & $\mathrm{V} 1$ & V2 & V3 & Units & Ref. \\
\hline \multirow{12}{*}{ Maize } & Emergence-end juvenile & 307 & 290 & 263 & ${ }^{\circ} \mathrm{C}$ days & Observed \\
\hline & End juvenile-floral initiation & 31 & 31 & 33 & ${ }^{\circ} \mathrm{C}$ days & Observed \\
\hline & Flag leaf-flowering & 15 & 15 & 18 & ${ }^{\circ} \mathrm{C}$ days & Observed \\
\hline & Flowering-start grain filling & 191 & 191 & 185 & ${ }^{\circ} \mathrm{C}$ days & Observed \\
\hline & Flowering - maturity & 620 & 620 & 589 & ${ }^{\circ} \mathrm{C}$ days & Observed \\
\hline & Day length photoperiod to flowering & 12.5 & 12.5 & 12.5 & hours & Default \\
\hline & Day length photoperiod for insensitivity & 24 & 24 & 24 & hours & Default \\
\hline & Base temperature & 10 & 10 & 10 & ${ }^{\circ} \mathrm{C}$ & Estimated \\
\hline & Grain maximum number per head & 530 & 530 & 530 & number & Estimated \\
\hline & Grain growth rate & 8 & 8 & 9 & mg/day & Estimated \\
\hline & Radiation use efficiency & 1.6 & 1.6 & 1.6 & $\mathrm{~g} / \mathrm{MJ}$ & Default \\
\hline & Transpiration use efficiency & 0.009 & 0.009 & 0.009 & $\mathrm{kPa}$ & Default \\
\hline \multirow[t]{11}{*}{ Millet } & Emergence-end juvenile & 430 & 400 & 315 & ${ }^{\circ} \mathrm{C}$ days & Observed \\
\hline & End juvenile-floral initiation & 112 & 112 & 112 & ${ }^{\circ} \mathrm{C}$ days/h & Default \\
\hline & Flag leaf-flowering & 60 & 60 & 60 & ${ }^{\circ} \mathrm{C}$ days & Observed \\
\hline & Flowering-start grain filling & 100 & 100 & 100 & ${ }^{\circ} \mathrm{C}$ days & Observed \\
\hline & Flowering - maturity & 548 & 457 & 508 & ${ }^{\circ} \mathrm{C}$ days & Observed \\
\hline & Regression of largest leaf area - intercept & -807 & -807 & -807 & $\mathrm{~mm}^{2}$ & Akponikpè et al. (2010) \\
\hline & Regression of largest leaf area - slope & 1137 & 1137 & 1137 & $\mathrm{~mm}^{2} /$ leaf & Akponikpè et al. (2010) \\
\hline & Grain number per head & 3500 & 2000 & 3200 & grain/head & Estimated \\
\hline & Grain growth rate & 0.42 & 0.42 & 0.42 & mg/grain/day & Akponikpè et al. (2010) \\
\hline & Radiation use efficiency & 1.3 & 1.3 & 1.3 & $\mathrm{~g} / \mathrm{MJ}$ & Akponikpè et al. (2010) \\
\hline & Transpiration use efficiency & 0.009 & 0.009 & 0.009 & $\mathrm{kPa}$ & Default \\
\hline
\end{tabular}

Table 2

Soil parameters used in the APSIM simulations.

\begin{tabular}{|c|c|c|c|c|c|c|c|c|c|}
\hline & \multicolumn{9}{|c|}{ Soil depth (cm) } \\
\hline & Acronym & $0-10$ & $10-20$ & $20-30$ & $30-40$ & $40-60$ & $60-80$ & units & Ref. \\
\hline Bulk Density & $\mathrm{BD}$ & 1.57 & 1.57 & 1.72 & 1.67 & 1.74 & 1.65 & $\mathrm{~g} / \mathrm{cm}^{3}$ & Measured \\
\hline Volumetric soil water content at the lower limit ${ }^{\text {a }}$ & LL & 0.148 & 0.14 & 0.171 & 0.114 & 0.086 & 0.107 & $\mathrm{~mm} / \mathrm{mm}$ & Measured \\
\hline Volumetric soil water content at the drained upper limit & DUL & 0.283 & 0.272 & 0.304 & 0.283 & 0.206 & 0.25 & $\mathrm{~mm} / \mathrm{mm}$ & Measured \\
\hline Volumetric soil water content at the saturation & SAT & 0.317 & 0.305 & 0.337 & 0.331 & 0.226 & 0.273 & $\mathrm{~mm} / \mathrm{mm}$ & Measured \\
\hline Soil water extraction coefficient & KL & 0.05 & 0.05 & 0.05 & 0.05 & 0.05 & 0.05 & /days & Estimated \\
\hline Layer drainage rate coefficient & SWCON & 0.4 & 0.4 & 0.4 & 0.4 & 0.4 & 0.4 & - & Estimated \\
\hline Inert fraction of organic carbon & FINERT & 0.2 & 0.2 & 0.35 & 0.35 & 0.899 & 0.89 & - & Sissoko (2009) \\
\hline Non-inert fraction of carbon in microbial products & FBIOM & 0.04 & 0.02 & 0.02 & 0.01 & 0.01 & 0.01 & - & Sissoko (2009) \\
\hline Soil albedo & SALB & 0.13 & & & & & & - & Sissoko (2009) \\
\hline Stage 1 soil evaporation coefficient & $\mathrm{U}$ & 8.65 & & & & & & $\mathrm{~mm}$ & Sissoko (2009) \\
\hline Stage 2 soil evaporation coefficient & CONA & 0.01 & & & & & & - & Sissoko (2009) \\
\hline Bare soil runoff curve number & CN2_BARE & 40 & & & & & & - & Sissoko (2009) \\
\hline Reduction in CN2_BARE due to cover & CN_RED & 28 & & & & & & - & Sissoko (2009) ${ }^{b}$ \\
\hline
\end{tabular}

a The volumetric soil water content at the lower limit was also used for the crop lower limit.

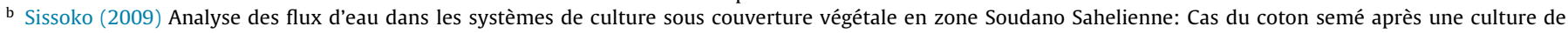
sorgho/brachiaria au sud du Mali. Thèse de Doctorat, Montpellier SupAgro, 169 pp.

practice (F1, being $60 \mathrm{~kg} \mathrm{~N} \mathrm{ha}^{-1}$ for maize and no $\mathrm{N}$ for millet). Subsequently, the effects of different cropping practices under current and future climate were explored by investigating effects of recommended fertilizer rates (F2, $85 \mathrm{~kg} \mathrm{~N} \mathrm{ha}^{-1}$ for maize and $40 \mathrm{~kg} \mathrm{~N} \mathrm{ha}^{-1}$ for millet), three planting dates (early (D1), medium (D2) and late (D3) planting) and two varieties, i.e. a short (V3) and a long (V1) duration variety.

The impact of future climate change on smallholder family food self-sufficiency was evaluated based on the balance of total energy produced and required at the household level. Total energy produced (kcal) was calculated based on the total cereal production on the farm and a crop-specific grain energy content (FAO, 1990). Energy requirements were calculated based on the number of household members and the average daily energy requirement per person $\left(2450 \mathrm{kcal}_{\text {person }}{ }^{-1}\right.$ day $^{-1}$ for adults and $1775 \mathrm{kcal}_{\text {person }}^{-1} \mathrm{day}^{-1}$ for children under the age of 11) (FAO and INPhO, 1993).

Based on findings of Sultan et al. (2013) indicating that millet and sorghum yields will be similarly affected by climate change, we assumed that the impact of climate change on millet, estimated in this study can also be applied to sorghum. Observed average yields of each farm type (Table A2) and total land areas were used to determine the current total farm production. The relative impacts of future climate change together with these observed average yields were used to calculate the expected absolute changes in yield and food production under the different scenarios of climate change and adaptation.

Farms were categorised into three farm types (Table A2) based on land holding, ownership of farming assets (plough, seeder, and cultivator), number of cattle and type of cropping system: a large farm type (6\% of the population), a medium farm type ( $81 \%$ of the population) and a small farm type ( $12 \%$ of the population) cultivating respectively 18, 10 and 4 ha of cropland (Djouara et al., 2006). For the farm type-specific adaptation options we assumed that the large farm type would apply the recommended fertilizer rate and keep the current early planting practice. The medium farm types would also apply recommended fertilizer rates and plant early in the growing season. As small farms usually struggle to plant on time because of lack of equipment such as plough, seeder and draught animals, we assumed that this type of farm would plant at medium planting date, but would apply recommended fertilizer rates.

Both single factor (climate, variety, fertilizer, planting date) and interaction effects on simulated maize and millet yields were esti- 
mated using ANOVA procedures (Tukey's test, at $P \leq 0.05$ ) (GenStat Edition 14 Library Release PL18.2, VSN International Ltd.).

\section{Results}

\subsection{Model performance}

Model performance for maize was good (Table 3 and Fig. 1). Simulated grain yields were relatively close to observed values for the different planting dates and varieties with $R^{2}$ values of 0.89 for 2010 (model calibration) and 0.69 for 2009 and 2011 (model tests). For total aboveground biomass the $R^{2}$ values were lower: 0.55 for 2010 and 0.56 for 2009 and 2011 (Fig. 1). Model efficiency for grain yield and total aboveground biomass was satisfactory for the three maize varieties (Table 3). Also LAI was adequately simulated (Fig. A1) with RMSE values for maximum LAI of $0.36,0.30$ and 0.34 for V1, V2 and V3 respectively and with model efficiency values that were higher than 0.95 for the three varieties (Table 3). Plant extractable soil water contents during the growing season were reasonably well simulated as indicated by the $R^{2}$ values between simulated and measured values $(0.69,0.72$ and 0.58 for respectively V1, V2 and V3 in 2010 and 0.52, 0.29 and 0.43 in 2010, Fig. A1).

Model performance for millet was satisfactory with $R^{2}$ values of 0.60 and 0.45 for grain yield simulations, respectively for the calibration year 2010 and the two test years 2009 and 2011 (Fig. 2). For total aboveground biomass, $R^{2}$ values were 0.53 and 0.71 for calibration and test datasets respectively. As indicated by the values of RMSE and model efficiency, the model adequately simulated total aboveground biomass, grain yield, maximum LAI and LAI dynamics for the three millet varieties (Table 3) (Fig. A2).

\subsection{Climate change predictions}

Climate predictions for the period 2040-2069 showed increased minimum and maximum temperatures (Fig. A3). In the simulated baseline climate of the past 30 years (1980-2009), average annual maximum and minimum temperatures were $34^{\circ} \mathrm{C}$ and $23^{\circ} \mathrm{C}$, respectively. In the rcp 8.5 scenario average annual maximum and minimum temperatures increased by $2.9^{\circ} \mathrm{C}$ and $3.3^{\circ} \mathrm{C}$ by mid-century (2040-2069) as compared with the baseline. The strongest warming occurred in May with an increase of $3.1^{\circ} \mathrm{C}$ and $3.7^{\circ} \mathrm{C}$ in maximum and minimum temperature, respectively (Fig. A3). The increase in August and September (the period of flowering and maturity of cereal crops) was $2.5^{\circ} \mathrm{C}$ and $2.6^{\circ} \mathrm{C}$ for maximum and minimum temperatures, respectively. Compared with the rcp8.5 scenario, the expected warming by mid-century was less pronounced under the rcp4.5 scenario (Fig. A3).

Predicted average annual rainfall for 2040-69 did not change significantly from the baseline with either emission scenario, nor did average monthly rainfall (Fig. A3). By mid-century, predicted average seasonal rainfall amount was $890 \mathrm{~mm}$ and $945 \mathrm{~mm}$ respectively for the rcp4.5 and rcp8.5 scenarios.

Despite the consistent trends of increased predicted minimum and maximum temperature compared with the baseline, there were large and significant differences $(P=0.001)$ between the five GCMs (Fig. A4). Under the rcp8.5 scenario, the highest growing season temperature was obtained with the ipsl model with an average of $28.6^{\circ} \mathrm{C}$ and $38.5^{\circ} \mathrm{C}$ respectively for minimum and maximum temperature, while the lowest growing season temperature was obtained with the cnrm model with an average of $25.2^{\circ} \mathrm{C}$ and $35.2^{\circ} \mathrm{C}$ respectively for minimum and maximum temperature (Fig. A4). The same differences between GCMs were observed under the rcp4.5 scenario (Fig. A4).

\subsection{Variability and uncertainty in grain yield predictions}

Under the baseline scenario the average coefficient of variation in simulated grain yield was $21 \%$ and $15 \%$ respectively for maize and millet. Predictions of maize and millet grain yields differed between the GCMs (Fig. 3). Under the rcp4.5 scenario, average yields of the long duration variety of maize (V1) simulated with climate data from the cnrm model were significantly $(P<0.05)$ larger than those simulated with climate data from the ipsl model, while yields obtained with hadgem 2 , mpi and ecearth data were similar (Table 4). The coefficient of variation in yield over the 30 years simulation period (2040-69) varied between 39\% (cnrm) and 68\% (ipsl). Under rcp8.5 ANOVA results indicated that average maize grain yields simulated with cnrm climate data were significantly $(P<0.001)$ larger than yields simulated with climate data from the other models except hadgem 2 . The coefficients of variation in yields varied from $39 \%$ (cnrm) to $88 \%$ (ipsl).

For millet, ANOVA results indicated significant $(P<0.01)$ differences in yields obtained with climate data from different GCMs both for the rcp4.5 and rcp8.5 scenarios. Under rcp4.5 the average yields simulated with data from the ecearth were significantly $(P<0.01)$ larger than yields simulated with climate data from the $\mathrm{cnrm}$ and hadgem 2 models while average yields obtained with ipsl and mpi data were similar. The coefficient of variation in simulated yields varied from $11 \%$ (hadgem 2 ) to $16 \%$ (cnrm). Under the rcp8.5 scenario, average yields simulated with climate data from ecearth were significantly $(P<0.001)$ larger than yields simulated with climate data from all other GCMs.

With results from all GCMs pooled, the average coefficient of variation of predicted maize grain yield over the 30 years simulation period was $53 \%$ and $60 \%$ for rcp 4.5 and rcp8.5, while for millet it was $14 \%$ for rcp 4.5 and $12 \%$ for rcp 8.5 respectively.

For maize the range in simulated yields between GCMs was $395 \mathrm{~kg} \mathrm{ha}^{-1}$ and $781 \mathrm{~kg} \mathrm{ha}^{-1}$ respectively under rcp4.5 and rcp8.5 while for millet it was $134 \mathrm{~kg} \mathrm{ha}^{-1}$ and $213 \mathrm{~kg} \mathrm{ha}^{-1}$ respectively. Therefore, it seems that the uncertainty in maize and millet yield predictions resulted from both GCM and RCP differences.

\subsection{Yield predictions under climate change with current fertilizer practices}

For the long duration variety (V1) of maize at early planting date (D1) the median predicted grain yield in the baseline climate scenario and with current fertilizer application rate (F1) was $2213 \mathrm{~kg} \mathrm{ha}^{-1}$ (Fig. 3). For future climate during the mid-century period (2040-69), the median predicted grain yield declined by $59 \%$ and $67 \%$ under the rcp 4.5 and rcp8.5 scenarios respectively. A similar impact of climate change was predicted for the short duration maize variety (V3) at early planting (D1), showing a decrease of 50\% and $58 \%$ under the rcp 4.5 and rcp 8.5 scenario respectively, relative to the median predicted baseline yield of $1733 \mathrm{~kg} \mathrm{ha}^{-1}$ (Fig. 3). Comparing the two maize varieties at early planting (D1), the median grain yield of the long duration variety (V1) was 22\% larger than that of the short duration variety (V3) under the baseline climate. The differences between varieties were smaller than $5 \%$ under future climate for both the rcp4.5 and rcp8.5 scenarios.

The median predicted grain yield under the baseline climate was $1199 \mathrm{~kg} \mathrm{ha}^{-1}$ for the long duration variety (V1) of millet at early planting (D1) and with current fertilizer application rate (F1) (Fig. 3). There was no predicted yield loss under rcp4.5 while for the rcp8.5 scenario, the predicted yield loss was $4 \%$ (Fig. 3). For the short duration variety (V3) of millet at early planting (D1), median predicted grain yield under the baseline scenario was $1101 \mathrm{~kg} \mathrm{ha}^{-1}$ (Fig. 3). Under future climate, median predicted yield loss was $0 \%$ for the scenario rcp 4.5 and $6 \%$ for the scenario rcp8.5. Comparing both millet varieties at early planting (D1) revealed that the 



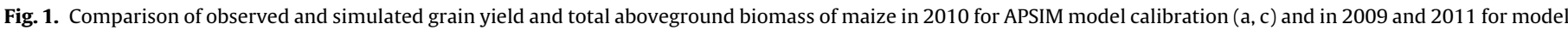

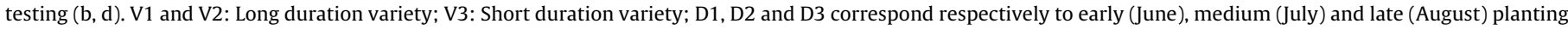
date. The $1: 1$ line is indicated in each graph.
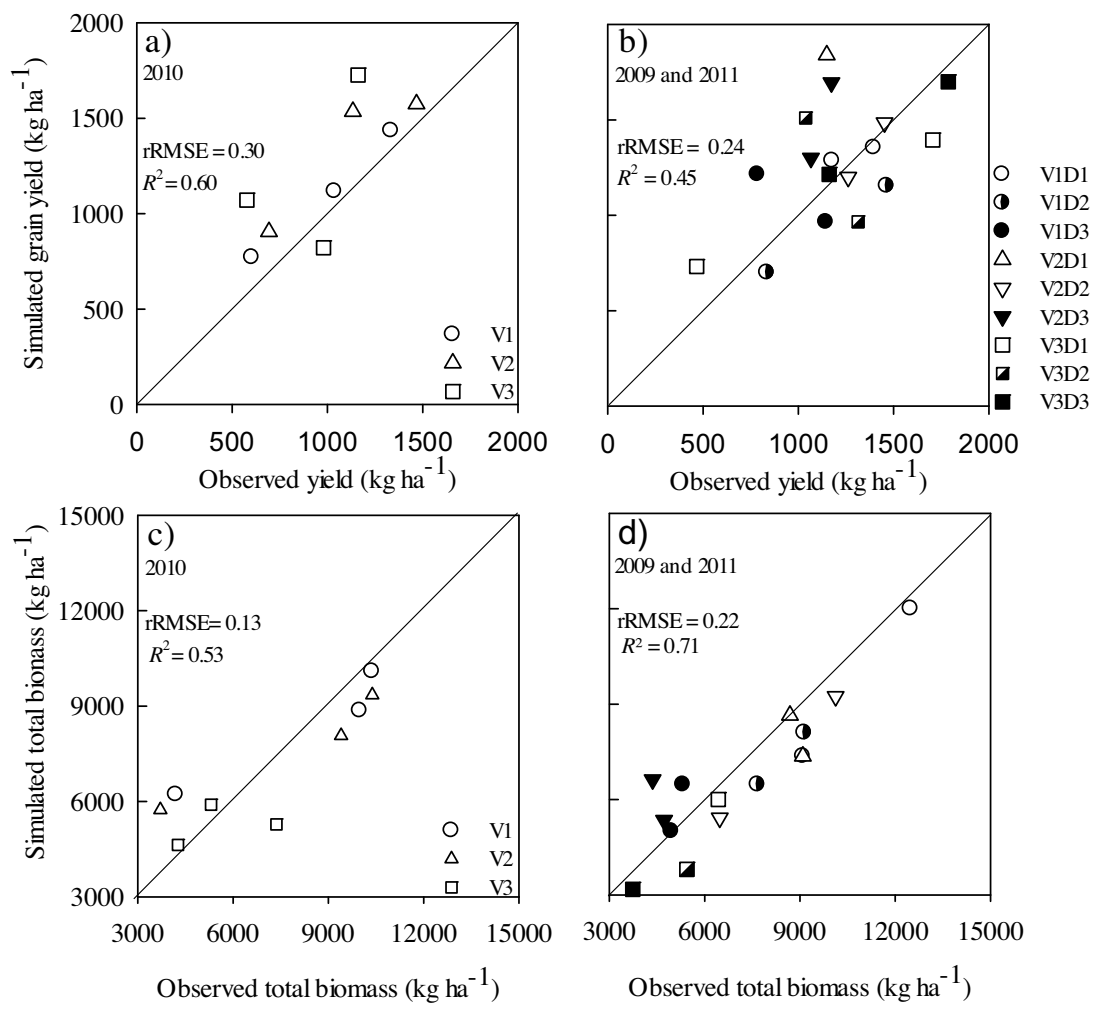

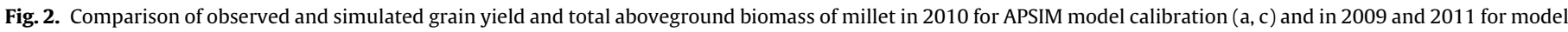

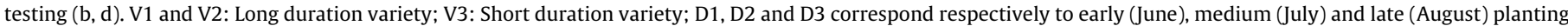
date. The $1: 1$ line is indicated in each graph. 
Table 3

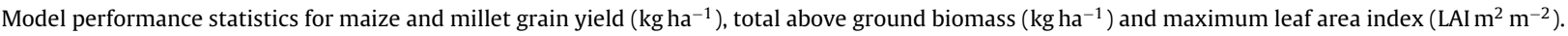

\begin{tabular}{|c|c|c|c|c|c|c|c|}
\hline & & \multicolumn{2}{|l|}{ V1 } & \multicolumn{2}{|l|}{ V2 } & \multicolumn{2}{|l|}{ V3 } \\
\hline & & RMSE & EFF & RMSE & EFF & RMSE & EFF \\
\hline \multirow[t]{3}{*}{ Maize } & grain yield & 397 & 0.54 & 497 & 0.15 & 463 & 0.38 \\
\hline & total aboveground ground biomass & 1333 & 0.65 & 1549 & 0.30 & 933 & 0.42 \\
\hline & LAI & 0.36 & 0.95 & 0.30 & 0.98 & 0.34 & 0.95 \\
\hline \multirow[t]{3}{*}{ Millet } & grain yield & 249 & 0.39 & 380 & 0.32 & 295 & 0.54 \\
\hline & total aboveground ground biomass & 1226 & 0.77 & 1316 & 0.64 & 2040 & 0.31 \\
\hline & LAI & 0.68 & 0.79 & 0.75 & 0.74 & 0.43 & 0.85 \\
\hline
\end{tabular}

RMSE: Root mean square error, EFF: efficiency of the model; V1 and V2: Long duration variety; V3: Short duration variety.

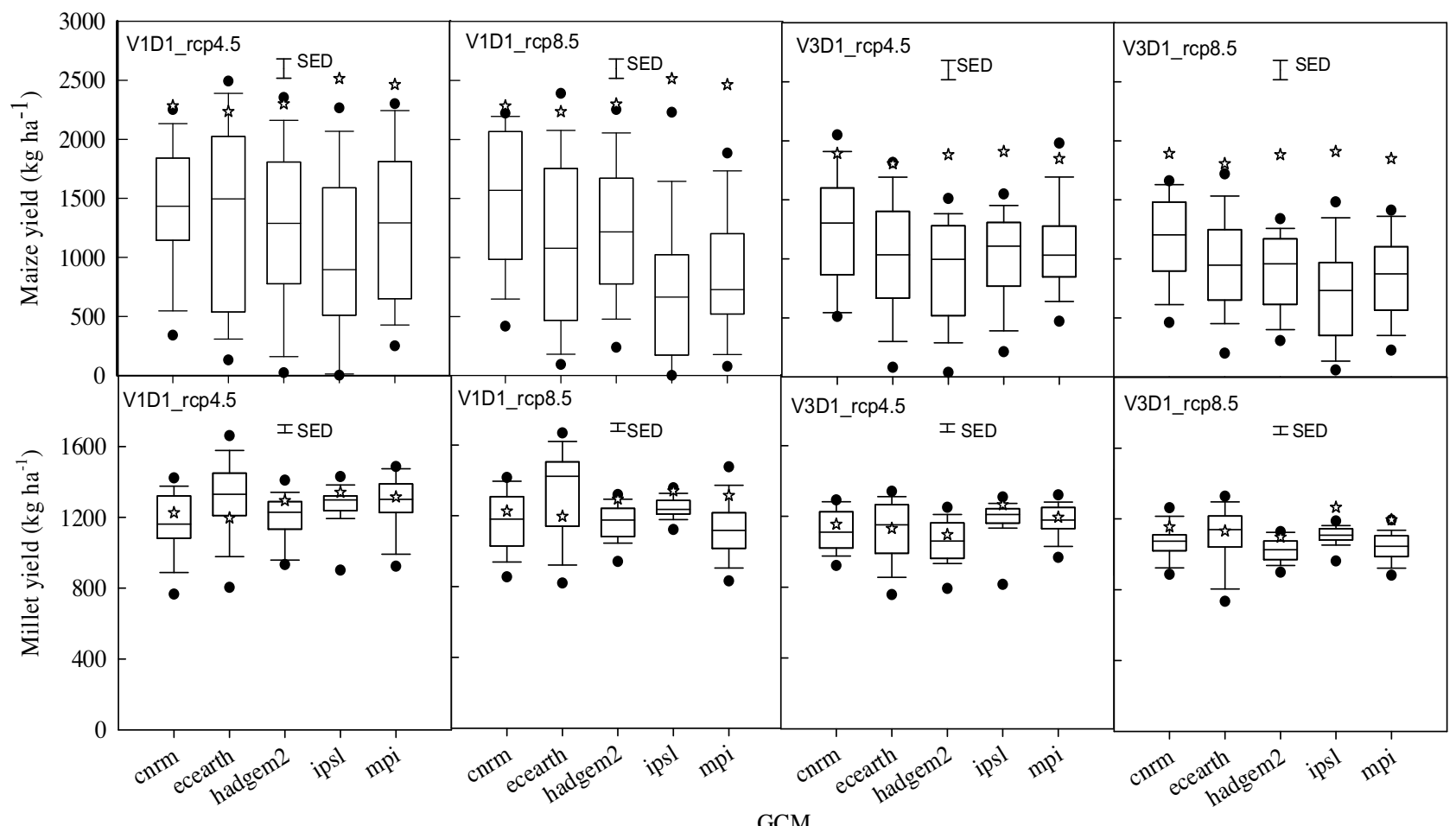

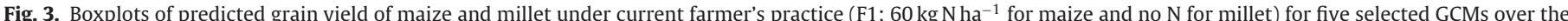

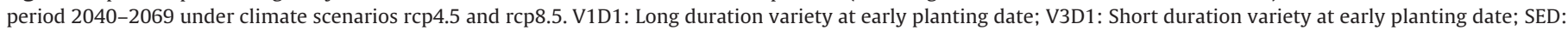
Standard error of the difference between means. The stars represent average simulated grain yield value under the baseline climate (1980-2009).

Table 4

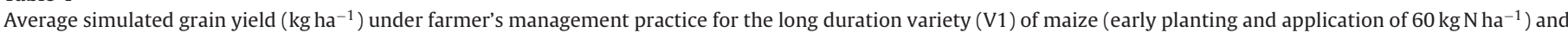

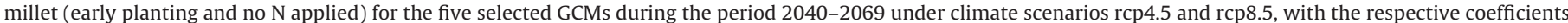
of variation (\%) between brackets.

\begin{tabular}{|c|c|c|c|c|}
\hline \multirow[t]{2}{*}{ GCM } & \multicolumn{2}{|l|}{ Maize } & \multicolumn{2}{|l|}{ Millet } \\
\hline & rсp4.5 & rсp8.5 & rсp4.5 & rcp8.5 \\
\hline ipsl & $1014^{\mathrm{a}}(68)$ & $708^{a}(88)$ & $1269^{\mathrm{abc}}(12)$ & $1241^{\mathrm{b}}(5)$ \\
\hline hadgem 2 & $1273^{\mathrm{ab}}(52)$ & $1258^{\mathrm{cd}}(45)$ & $1198^{\mathrm{ab}}(11)$ & $1161^{\mathrm{ab}}(9)$ \\
\hline mpi & $1306^{\mathrm{ab}}(50)$ & $864^{\mathrm{ab}}(63)$ & $1282^{\mathrm{bc}}(12)$ & $1128^{a}(15)$ \\
\hline ecearth & $1377^{\mathrm{ab}}(57)$ & $1093^{\mathrm{bc}}(64)$ & $1309^{c}(17)$ & $1341^{c}(19)$ \\
\hline $\mathrm{cnrm}$ & $1409^{b}(39)$ & $1489^{d}(39)$ & $1175^{\mathrm{a}}(16)$ & $1172^{\mathrm{ab}}(14)$ \\
\hline
\end{tabular}

Different superscript letter (a, b) per column indicate significant differences (Tukey's test, $P<0.05$ ) in the mean value.

median predicted yield of the long duration variety (V1) was $8 \%$ larger than that of the short duration variety (V3) under the baseline climate. This difference remained similar under future climate of the mid-century period for both emission scenarios.

The yield decline was mainly caused by the impact of the predicted temperature increase, while predicted changes in rainfall only had a minor or no effect under both scenarios rcp4.5 and rcp8.5. This is illustrated in Fig. 4 for rcp8.5, showing that a fic- titious climate scenario, in which historical rainfall is coupled with future temperature as predicted by GCMs, had the same effect on simulated maize and millet grain yields as the future scenario with both future temperature and rainfall as predicted by GCMs.

Linear regression analysis indicated a significant $(P<0.001)$ shortening of the predicted time to flowering by mid-century for both varieties of maize and millet (Fig. 5). For the long duration variety (V1) of maize, the simulated time to flowering was short- 


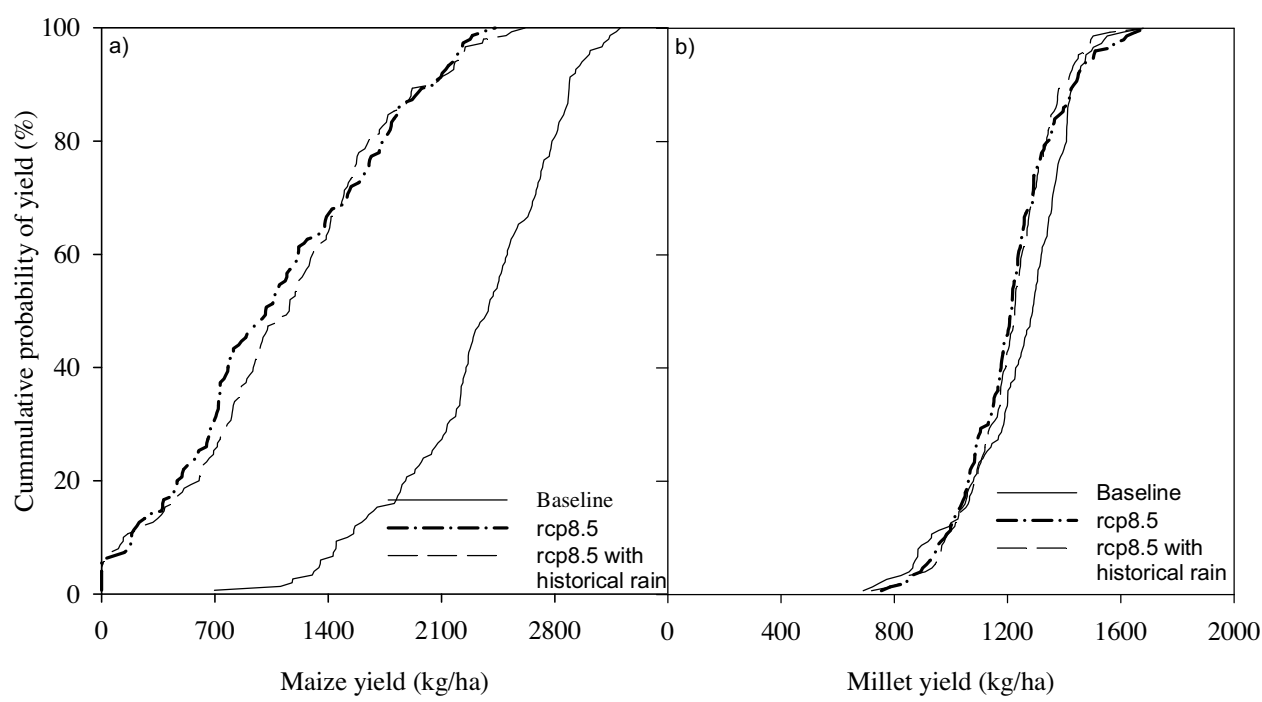

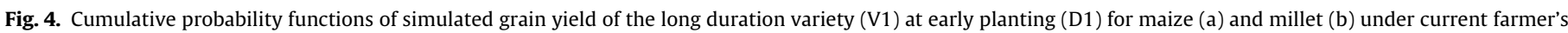

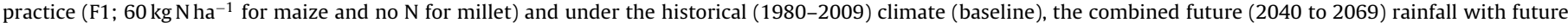

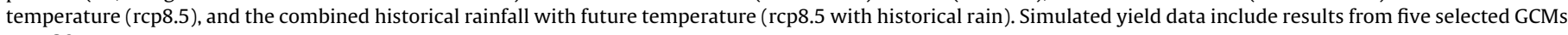
over 30 years.

ened by 2.5 days and 4 days under rcp 4.5 and rcp8.5 respectively, while for the short duration variety (V3) the shortening was 2 and 3 days over the period 2010-2069. For millet the simulated time to flowering was shortened by 2 days for both the long (V1) and short (V3) duration varieties under scenario rcp4.5. Under rcp8.5, the shortening was 4 and 3 days for the long (V1) and short (V3) duration variety respectively over the period 2010-2069.

\subsection{Evaluating adaptation options to future climate change}

\subsubsection{Maize}

There was a significant interaction effect of climate on the fertilizer - maize grain yield relationship (Table 5 ). Predicted grain yield losses under future mid-century climate were $51 \%$ and $57 \%$ with current farmer practice of fertilization ( $\left.F 1,60 \mathrm{~kg} \mathrm{~N} \mathrm{ha}^{-1}\right)$ under the rcp4.5 and rcp8.5 scenarios respectively. With recommended fertilizer application (F2, $85 \mathrm{~kg} \mathrm{~N} \mathrm{ha}^{-1}$ ) simulated yield losses under rcp 4.5 and rcp8.5 were reduced to respectively $46 \%$ and $51 \%$.

At early (D1) and medium (D2) planting the simulated climate change impacts were a yield loss of, respectively, $47 \%$ and $53 \%$ for rcp 4.5 and of $53 \%$ and $60 \%$ for rcp8.5. At late planting (D3), which resulted in very low grain yields, the relative yield losses were about $70 \%$ under both emission scenarios (Table 5).

Whereas recommended fertilizer rate application improved grain yields under both the current and future climate, the predicted effect was negligible if planting was late (D3) (Fig. 6). Also, the predicted fertilizer effect was stronger for the long duration variety (V1) as compared with the short duration variety (V3) both for the baseline and the future climate scenarios. If planting was delayed strongly (D3), the short duration variety (V3) was a good alternative, whereas with a slight delay of planting (D2), the long duration variety (V1) still yielded more. When planting was delayed under the future climate, the differences between the maize varieties dissipated (Fig. 6).

\subsubsection{Millet}

Simulated grain yield obtained with recommended fertilizer practice F2 (39 $\mathrm{kg} \mathrm{N} \mathrm{ha}^{-1}$ ) was larger than with farmer practice (F1, $0 \mathrm{~kg} \mathrm{~N} \mathrm{ha}^{-1}$ ) by about $29 \%$ under baseline climate, by $22 \%$ under the rcp 4.5 scenario and by $20 \%$ under the rcp 8.5 scenario (Table 5). If the recommended fertilizer rates were applied, the predicted yield losses under farmer practice due to climate change were offset for both emission scenarios (Table 5). With recommended fertilizer, a yield loss of $8 \%$ and $15 \%$ was predicted at early (D1) and medium (D2) planting under both emission scenarios. Delaying planting from D1 to D3 caused a strong yield loss across the baseline and future climates. A similar significant effect of climate change on grain yield was predicted for the long duration (V1) and short duration (V3) varieties, with simulated yield losses of $10 \%$ and $14 \%$, and $11 \%$ and $17 \%$ under the rcp 4.5 and rcp8.5 scenarios respectively (Table 5).

A strong yield increase was predicted with recommended fertilizer rates (F2) for the long duration variety (V1), especially at early planting (D1) under the current climate (Fig. 6). Under both emission scenarios fertilizer was predicted to largely offset the negative effect of climate change on the long duration millet variety (V1). For the short duration variety (V3) on the other hand, applying recommended fertilizer rates reversed the climate change effect for D1 and D2, but not for D3 under both emission scenarios.

\subsection{Impact of future climate change on family food self-sufficiency}

Under the current climate conditions, the food needs of the large and medium farms were satisfied by on-farm production while the small farm type did not achieve this (Table 6). Under future climate and current cropping practices, food availability was reduced for all farm types, but large farms still achieved food self-sufficiency (Table 6). The medium farms dropped below the self-sufficiency threshold and small farms experienced a further decrease in food self-sufficiency. Under future climate conditions, large farms increased their food self-sufficiency status by applying recommended fertilizer rates (Table 6). Medium farms raised food self-sufficiency above $100 \%$ by advancing planting from the current medium planting date (D2) to early planting date (D1). Applying the recommended fertilizer rates in combination with early planting further increased food production, whereas applying recommended fertilizer rates without earlier planting was insufficient to reach food self-sufficiency. For small farms, planting earlier and/or applying the recommended fertilizer rates was insufficient to achieve food self-sufficiency under future climate conditions. 

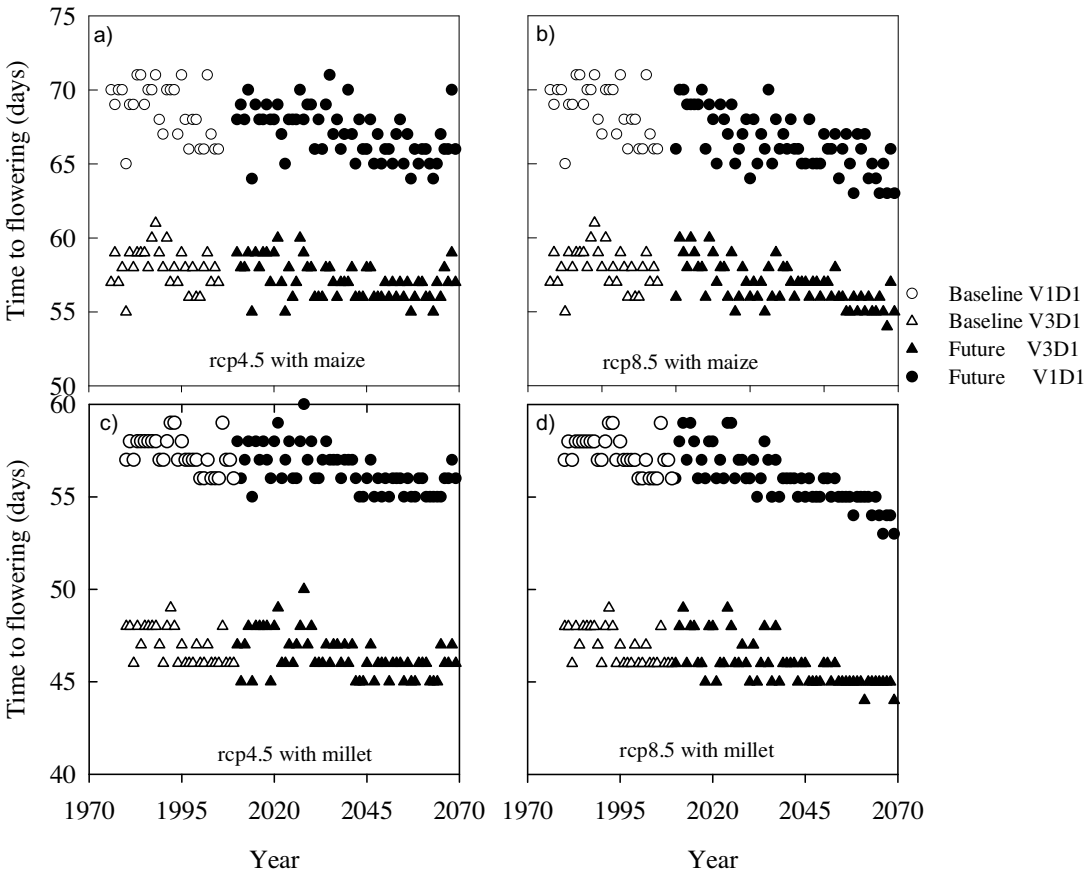

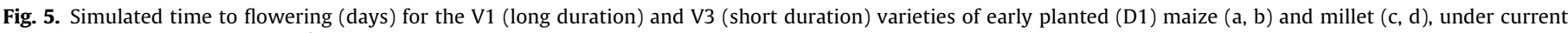

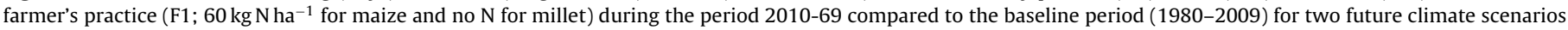
(rcp4.5 and 8.5). Simulated data include results from five selected GCMs.

Table 5


mid-century (2040-2069) climate under the rcp4.5 and rcp8.5 scenarios.

\begin{tabular}{|c|c|c|c|c|c|c|c|}
\hline & \multirow[b]{2}{*}{ Factor } & \multicolumn{3}{|l|}{ Maize } & \multicolumn{3}{|l|}{ Millet } \\
\hline & & Baseline & rсp4.5 & rcp8.5 & Baseline & rcp4.5 & rcp8.5 \\
\hline \multirow[t]{4}{*}{ Fertilizer } & $\mathrm{F} 1$ & 1554 & 768 & 669 & 1010 & 935 & 884 \\
\hline & $\mathrm{F} 2$ & 1857 & 845 & 764 & 1303 & 1138 & 1064 \\
\hline & $P$ & 0.001 & & & 0.001 & & \\
\hline & SED & 23 & & & 9 & & \\
\hline \multirow{5}{*}{$\begin{array}{l}\text { Planting } \\
\text { date }\end{array}$} & D1 (Early) & 2320 & 1240 & 1082 & 1462 & 1375 & 1313 \\
\hline & D2 (Medium) & 2107 & 985 & 844 & 1062 & 937 & 867 \\
\hline & D3 (Late) & 689 & 194 & 225 & 945 & 797 & 743 \\
\hline & $P$ & 0.001 & & & 0.001 & & \\
\hline & SED & 28 & & & 11 & & \\
\hline \multirow[t]{4}{*}{ Variety } & V1(Long duration) & 1844 & 840 & 712 & 1248 & 1123 & 1067 \\
\hline & V3 (Short duration) & 1566 & 772 & 722 & 1065 & 950 & 881 \\
\hline & $P$ & 0.001 & & & 0.055 & & \\
\hline & SED & 23 & & & 9 & & \\
\hline
\end{tabular}

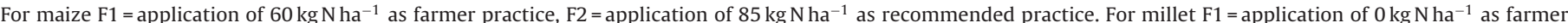



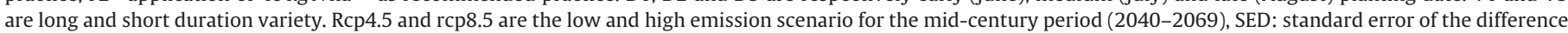
between means.

\section{Discussion}

Under both emission scenarios ( $\mathrm{rcp} 4.5$ and rcp8.5) temperatures are predicted to increase in southern Mali with strong negative consequences for crop productivity, especially maize. If crop management is improved (if delays in planting date are avoided, recommended fertilization rates used and the best performing crop varieties chosen), the loss in crop yield due to climate change can be compensated and even turned into an increase compared with current yields. We now discuss our main findings in more detail, and draw conclusions on the consequences for smallholder family food self-sufficiency.

\subsection{Climate change in southern Mali}

The current trend of climate warming in southern Mali (Traore et al., 2013) will continue and even increase in speed, resulting in an increase of maximum and minimum temperature of 2.9 and $3.3^{\circ} \mathrm{C}$ respectively by the mid-century period (2040-2069). This result is corroborated across the three main ecological zones (Sudanian, Sahelian and Sahelo-Saharan) of West Africa (CEDEAOClubSahel/OCDE/CILSS, 2008). As a consequence, temperature thresholds with negative effects on crop yields that used to be reached rarely, are now attained more frequently (Stott et al., 2004). This trend will intensify by mid-century if greenhouse gas emissions continue unabated (Stott et al., 2011). The geographically widespread warming trend in West Africa includes a tendency of 

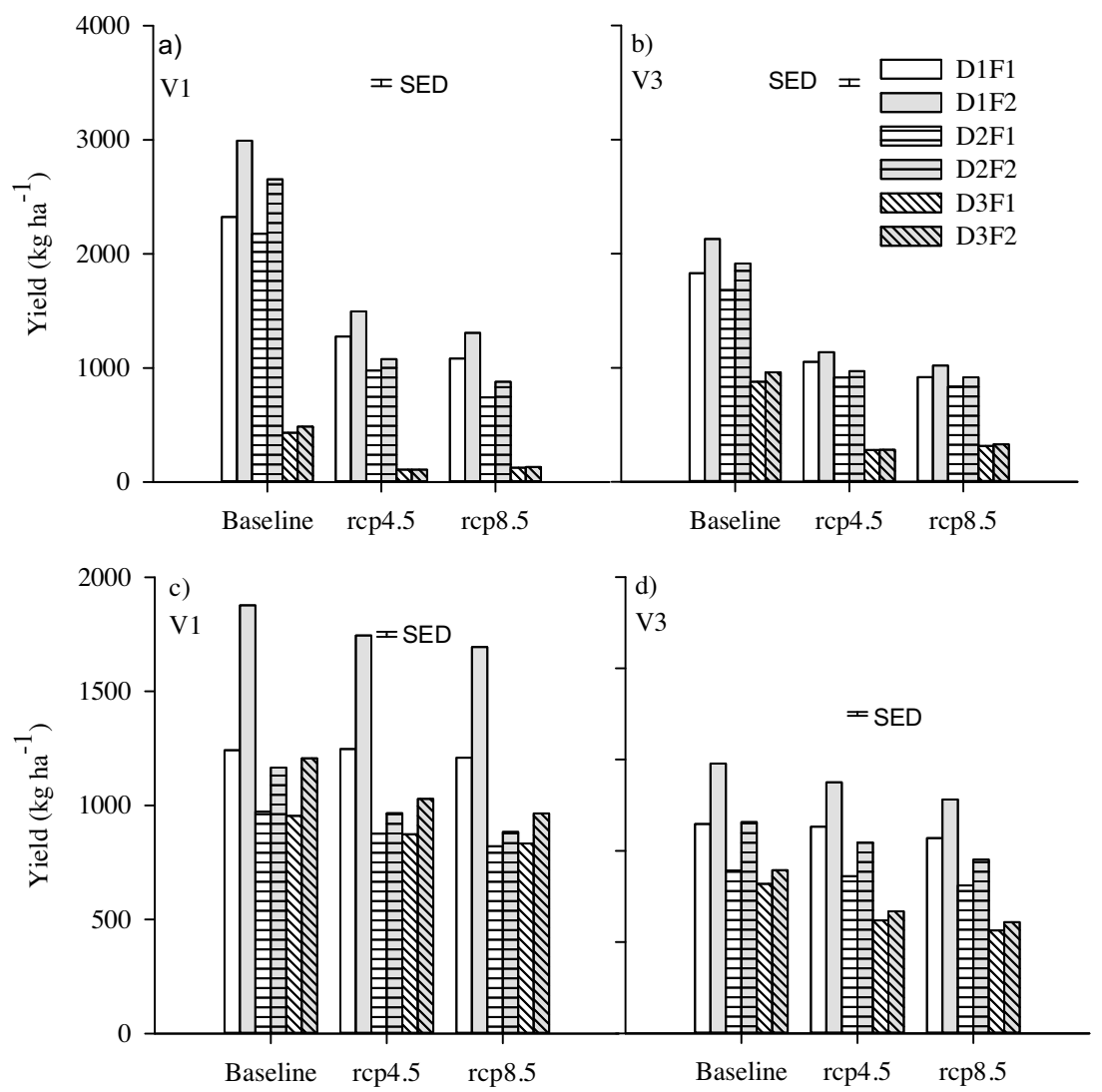

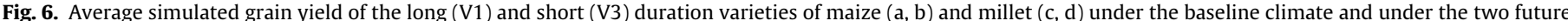

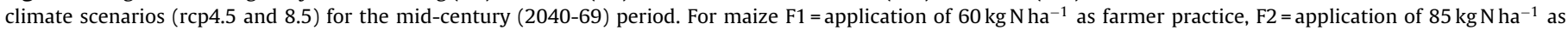

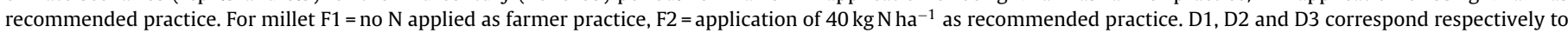
early (June), medium (July) and late (August) planting. SED: Standard error of the difference between means.

Table 6

Future climate change impact on the food self-sufficiency of large, medium and small farm types.

\begin{tabular}{|c|c|c|c|c|c|c|c|}
\hline & Cropping practice & & Climate & $\begin{array}{l}\text { Maize } \\
\left(\mathrm{kg} \mathrm{farm}^{-1}\right)\end{array}$ & $\begin{array}{l}\text { Millet } \\
\left(\operatorname{kg~farm}^{-1}\right)\end{array}$ & $\begin{array}{l}\text { Sorghum } \\
\left(\mathrm{kg} \mathrm{farm}^{-1}\right)\end{array}$ & $\begin{array}{l}\text { Food self-sufficiency (\%, } \\
\text { expressed in kcal terms) }\end{array}$ \\
\hline \multirow[t]{5}{*}{ Large farm } & \multirow[t]{3}{*}{ Current practice } & Baseline & 2451 & 4927 & 7390 & 176 & \\
\hline & & rcp4.5 & 1605 & 4457 & 6685 & 152 & \\
\hline & & rcp8.5 & 1538 & 4542 & 6163 & 146 & \\
\hline & \multirow[t]{2}{*}{ Adaptation option } & Fertilizer & rсp4.5 & 1944 & 6149 & 9224 & 206 \\
\hline & & & rcp8.5 & 1939 & 6063 & 9094 & 204 \\
\hline \multirow[t]{9}{*}{ Medium farm } & \multirow[t]{3}{*}{ Current practice } & Baseline & 3650 & 1503 & 3506 & 103 & \\
\hline & & rcp4.5 & 2679 & 1393 & 3251 & 87 & \\
\hline & & rсp8.5 & 2568 & 1386 & 3235 & 85 & \\
\hline & \multirow[t]{6}{*}{ Adaptation option } & $\mathrm{F} 2 * \mathrm{D} 1$ & rсp4.5 & 4851 & 2022 & 4979 & 141 \\
\hline & & D1 & & 4005 & 1907 & 4696 & 126 \\
\hline & & $\mathrm{F} 2$ & & 2986 & 1477 & 3447 & 94 \\
\hline & & $\mathrm{F} 2 * \mathrm{D} 1$ & rсp8.5 & 4840 & 1979 & 4874 & 139 \\
\hline & & D1 & & 3838 & 1897 & 4672 & 124 \\
\hline & & $\mathrm{F} 2$ & & 2979 & 1446 & 3375 & 93 \\
\hline \multirow[t]{9}{*}{ Small farm } & \multirow[t]{3}{*}{ Current practice } & & Baseline & 693 & 1802 & 970 & 41 \\
\hline & & & rсp4.5 & 678 & 1746 & 940 & 40 \\
\hline & & & rcp8.5 & 650 & 1694 & 912 & 39 \\
\hline & \multirow[t]{6}{*}{ Adaptation option } & $\mathrm{F} 2 * \mathrm{D} 2$ & rcp 4.5 & 756 & 1974 & 1148 & 46 \\
\hline & & D2 & & 497 & 1862 & 992 & 40 \\
\hline & & $\mathrm{F} 2$ & & 558 & 1771 & 1031 & 40 \\
\hline & & $\mathrm{F} 2 * \mathrm{D} 2$ & rсp8.5 & 754 & 1932 & 1091 & 45 \\
\hline & & D2 & & 482 & 1662 & 963 & 37 \\
\hline & & $\mathrm{F} 2$ & & 577 & 1734 & 979 & 39 \\
\hline
\end{tabular}

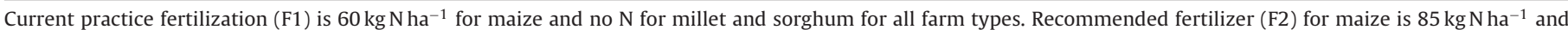

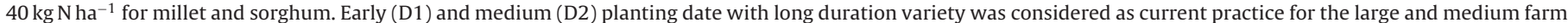

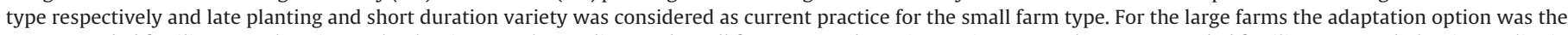




the small farm type. In the study site the large, medium and small farm types represented respectively 7,81 and $12 \%$ of the total farm population. 
drier regions to warm up more rapidly than wetter regions (Dai et al., 2004).

We found no clear changes in the monthly or annual amounts of rainfall for the near future while over West Africa there is low to medium confidence in projected changes of rainfall (Niang et al., 2014). Extremely dry and wet years will likely become more frequent during the 21st century (Dai et al., 2004) and the increase of temperature in future will likely lead to higher soil evaporation losses and thus drying of topsoil layers, thereby potentially increasing the intensity and duration of droughts (Trenberth, 2011).

\subsection{Effect of climate change on maize and millet yields}

Both long and short duration maize and millet varieties are negatively affected by climate change. Our model predictions suggest that the temperature increase will substantially reduce grain yields, especially of maize, strongly affecting food production in the Sudano-Sahelian zone. Our findings resulting from a locally calibrated and tested crop growth model add evidence to several studies that have predicted the potential impact of future climate change on the performance of sub-Saharan Africa agriculture (Barrios et al., 2008; Sultan et al., 2013; Serdeczny et al., 2016). We found a large variability in future climate impact on yield of maize and millet. This large variability is in line with findings of Fischer et al. (2001) and Parry et al. (2004) showing that the magnitude of crop yield responses to climate change in sub-Saharan Africa varied considerably from $-98 \%$ to $+16 \%$ although in most cases predicted changes are negative (Challinor et al., 2007). This large variability in predicted yields is largely explained by spatial variability and by differences in the type of climate and crop growth simulation methods used.

The negative impacts of increased temperatures on yields of maize, and to a lesser extent millet, highlight the importance of coping with global warming, especially for resource-limited smallholder farmers. In the Sudano-Sahelian region, poor soil fertility and inappropriate management practices are a major cause of low crop productivity. Separating these factors from effects of climate change and variability is not straightforward (Simelton et al., 2013), but our results showed that current cropping systems with low fertilizer input (e.g. millet), are less sensitive to climate change than cropping systems with higher fertilizer input (e.g. maize). As cropping systems intensify, good management in terms of timely planting and choosing adapted varieties becomes essential to cope with climate change.

With no clear predicted change in rainfall in our study, the predicted climate impact was primarily related to increased temperature. However, a possible rainfall change may have an impact on the crop response to temperature increase. For example, for a millet variety in Niger, it was predicted that changes in rainfall strongly affected the negative effects of increased temperature $\left(+1.5^{\circ} \mathrm{C}\right)$, with a $59 \%$ versus $26 \%$ crop yield loss for decreasing and increasing rainfall respectively (Salack and Traore, 2006). Similarly, Roudier et al. (2011) showed that rainfall changes, still uncertain in climate projections, have the potential to aggravate or moderate impact due to temperature depending on whether rainfall decreases or increases.

Our results showed that a key cause of lower crop yields is the reduction of the time to flowering, thereby reducing the effective period during which biomass and assimilate build-up before grain filling can take place. We found that by mid-century for the rcp 4.5 and rcp 8.5 scenarios respectively, $28 \%$ and $38 \%$ of daily maximum temperatures during the growing period were higher than the threshold value of $38^{\circ} \mathrm{C}$ above which APSIM simulates the effect of heat stress on the number of maize grains. For both scenarios, $57 \%$ of the daily mean temperatures were above the threshold value of $30^{\circ} \mathrm{C}$ maize grain filling is negatively affected in APSIM (Fig. A5).
Simulated photosynthesis is also negatively affected by increased temperatures: by mid-century $8 \%$ of daily mean temperatures were above the threshold value of $35^{\circ} \mathrm{C}$ for both crops. For maize the three processes (grain formation, grain filling and photosynthesis) were affected by the predicted temperature increases, while for millet only phenology and grain filling were affected. The large difference in the predicted yield responses between maize and millet to climate change indicates that the effect of the predicted temperature increase on grain number is large.

Although with current practices maize productivity was more strongly impacted by climate change than millet productivity, poor yields (less than $1200 \mathrm{~kg} \mathrm{ha}^{-1}$ ) were obtained more frequently with millet than with maize, both for long and short duration varieties (Fig. 4). It means that the trend of expansion of maize cultivation (Soumaré et al., 2004) is likely to continue, despite the potential strong decline in predicted yields under climate change.

\subsection{Adaptation options for family food-sufficiency}

To achieve family food self-sufficiency current crop management strategies need to be improved. The effectiveness of changing planting date as an adaptation option varies according to farm type (Table 3). Early planting is an important option to achieve food self-sufficiency for the medium-sized farms. Other studies (Kamara et al., 2009) have also shown the importance of planting date for enhancing crop productivity. The adoption of earlier planting will to a great extent depend on improvement of current planting techniques, which currently rely on a rudimentary seeder that has not evolved since its introduction in 1960 (FAO, 2008). More efficient seeders would allow faster planting of a larger area allowing farmers to take advantage of the first rains (Traore, 2014).

Although farmers are aware of the beneficial effects of mineral fertilizer on crop productivity, access to a secure and affordable supply remains the main constraint. Besides increasing the amounts of fertilizer used, fertilizer use efficiency needs to be improved (de Ridder et al., 2004). For instance, micro-dosing or hill application can improve fertilizer use efficiency, resulting in increased crop yields and farmer's income (Sawadogo-Kaboré et al., 2009). Yet the smaller farmers remain food insecure even when improving the planting date from late to medium and applying the recommended fertilizer rates because of their limited cropped area. Achieving food security for this group of farmers will require off-farm activities given their land constraints. By disaggregating the climate change impact assessment by farm type, adaptation options and strategies can be tailored to specific farm contexts, thus increasing their relevance and likelihood of adoption.

\subsection{Uncertainty in projections and its implications}

Our results showed large uncertainty in yield predictions with the different GCMs and RCPs both for maize and millet. This uncertainty primarily stems from the variations in the way GCMs respond to changes in atmospheric forcing (Teng et al., 2012), which is associated with the structure of the climate models, model parameterization, and also with spatial resolution. Based on these uncertainties, it can be inferred that results obtained with a group or ensemble of GCMs are more reliable than results obtained with individual GCMs. Asseng et al. (2013) showed that the uncertainty in climate change impact projections also results from the choice of crop models. It is therefore suggested to use multi-crop model ensembles in a similar way as the use of multi GCM ensembles. Our results obtained with a single crop growth simulation model should therefore be interpreted with this limitation in mind. 


\section{Conclusion}

With both emission scenarios, i.e. the worst case scenario (rcp8.5) and a lower emission scenario (rcp4.5), temperatures in southern Mali will continue to increase. The rise in temperature has negative consequences for crop productivity and food self-sufficiency. Our model predictions suggest that under future climate change, the large and medium farms can remain food selfsufficient. Adaptation of crop management through early planting, increased fertilizer rates and adapted crop varieties is essential to cope with climate change. Smaller farms are likely not to achieve food self-sufficiency under any of these management scenarios and will need off-farm employment or some form of social support. Decision making by extension and development agents and policy makers can be supported by these place-based findings that apply to the Sudano-Sahelian zone of West Africa.

\section{Acknowledgements}

We thank the International Development Research Centre (IDRC) and Department for International Development (DFID) for funding through the Climate Change Adaptation in Africa (CCAA) Grant to the University of Zimbabwe. Additional funding from the Institut D'Economie Rurale du Mali is gratefully acknowledged. We thank the World Climate Research Programme's Working Group on Coupled Modelling, which is responsible for CMIP, and the climate modelling groups (CNRM-CM5, ECEARTH, HADGEM2-ES, IPSL-CM5A-LR, MPI-ESM-LR) for making available their model output. We are grateful to Neil Huth, Myriam Adam, Irenikatche Akponikpè and Dilys MacCarthy for help with the APSIM model.

\section{Appendix A. Supplementary data}

Supplementary data associated with this article can be found, in the online version, at http://dx.doi.org/10.1016/j.fcr.2016.11.002.

\section{References}

Akponikpè, P.B.I., Gérard, B., Michels, K., Bielders, C., 2010. Use of the APSIM model in long term simulation to support decision making regarding nitrogen management for pearl millet in the Sahel. Eur. J. Agron. 32, 144-154.

Asseng, S., Ewert, F., Rosenzweig, C., Jones, J.W., Hatfield, J.L., Ruane, A.C., Boote, K.J., Thorburn, P.J., Rötter, R.P., Cammarano, D., 2013. Uncertainty in simulating wheat yields under climate change. Nat. Clim. Change 3, 827-832.

Barrios, S., Ouattara, B., Strobl, E., 2008. The impact of climatic change on agricultural production: is it different for Africa? Food Policy 2, 287-298.

Butt, T.A., McCarl, B.A., Angerer, J., Dyke, P.T., Stuth, J.W., 2005a. The economic and food security implications of climate change in mali. Clim. Change 68, 355-378.

Butt, T.A., McCarl, B.A., Kergna, A.O., 2005b. Policies for reducing agricultural sector vulnerability to climate change in Mali. Climate Policy 5, 581-596.

CEDEAO-ClubSahel/OCDE/CILSS, 2008. Climate and climate change.The atlas on regional integration in West Africa. Environment series, p.13.

Challinor, A., Wheeler, T., Garforth, C., Craufurd, P., Kassam, A., 2007. Assessing the vulnerability of food crop systems in Africa to climate change. Clim. Change 83, 381-399.

Chuku, C.A., Okoye, C., 2009. Increasing resilience reducing vulnerability in sub-Saharan African agriculture: strategies for risk coping and management. Afr. J. Agric. Res. 4, 1524-1535.

Dai, A., Lamb, P.J., Trenberth, K.E., Hulme, M., Jones, P.D., Xie, P., 2004. The recent Sahel drought is real. Int. J. Climatol. 24, 1323-1331.

de Ridder, N., Breman, H., van Keulen, H., Stomph, T.J., 2004. Revisiting a 'cure against land hunger': soil fertility management and farming systems dynamics in the West African Sahel. Agric. Syst. 80, 109-131.

Deveze, J.C., 2006. Le devenir des agricultures cotonnières: Cas du Mali. AFD, Mali.

Djouara, H., Bélières, J.F., Kébé, D., 2006. Les exploitations agricoles familiales de la zone cotonnière du Mali face à la baisse des prix du coton-graine. Cahiers Agricultures 15, 1-8

FAO and INPhO, 1993. Rice in human nutrition, Rome.

FAO, 1990. Protein quality evaluation. Report of a Joint FAO/WHO Expert Consultation, Bethesda, MD, USA, 4-8 December 1989. Rome, FAO. 66 pp.

FAO, 2008. Agricultural mechanization in Africa. Time for action: planning investment for enhanced agricultural productivity. Report of an expert group meeting jointly held by FAO and UNIDO in Vienna on 29-30 November 2007. Rome, FAO. 26 pp.
Fischer, G.M., Shah H., van Velthuizen, F.O., Nachtergaele, 2001. Global agro-ecological assessment for agriculture in the 21 st century: Methodology and Results. International Institute for Applied Systems Analysis, Vienna, 119 pp.

Fischer, G., Shah, M., Tubiello, F., VanVelhuizen, H., 2005. Socio-economic and climate change impacts on agriculture: an integrated assessment, 1990-2080. Philos. Trans. R. Soc. Biol. Sci. 360, 2067-2083.

Fraser, E.D.G., Dougill, A.J., Hubacek, K., Quinn, C.H., Sendzimir, J., Termansen, M., 2011. Assessing vulnerability to climate change in dryland livelihood systems: conceptual challenges and interdisciplinary solutions. Ecol. Soc. 16, 01.

Giller, K.E., Tittonell, P., Rufino, M.C., van Wijk, M.T., Zingore, S., Mapfumo, P. Adjei-Nsiah, S., Herrero, M., Chikowo, R., Corbeels, M., Rowe, E.C., Baijukya, F., Mwijage, A., Smith, J., Yeboah, E., van der Burg, W.J., Sanogo, O.M., Misiko, M., de Ridder, N., Karanja, S., Kaizzi, C., K'ungu, J., Mwale, M., Nwaga, D., Pacini, C., Vanlauwe, B., 2011. Communicating complexity: integrated assessment of trade-offs concerning soil fertility management within African farming systems to support innovation and development. Agric. Syst. 104, 191-203.

Haddeland, I., Heinke, J., Voß, F., Eisner, S., Chen, C., Hagemann, S., Ludwig, F., 2012. Effects of climate model radiation, humidity and wind estimates on hydrological simulations. Hydrol. Earth Syst. Sci. 16, 305-318.

IPCC, 2013. Summary for policymakers. In: T.F. Stocker, D., Qin, G.K., Plattner, M., Tignor, S.K., Allen, J., Boschung, A., Nauels, Y., Xia, B.Y., Midgley, P.M. (Eds.), Climate Change 2013: The Physical Science Basis. Contribution of Working Group I to the Fifth Assessment Report of the Intergovernmental Panel on Climate Change. Cambridge University Press, Cambridge, United Kingdom and New York, NY, USA

IPCC, I., 2014. Climate Change 2014: Impacts, Adaptation, and Vulnerability. Part A Global and Sectoral Aspects. Contribution of Working Group II to the Fifth Assessment Report of the Intergovernmental Panel on Climate Change. In: Field, C.B., Barros, V.R., Dokken, D.J., Mach, K.J., Mastrandrea, M.D., Bilir, T.E., Chatterjee, M., Ebi, K.L., Estrada, Y.O., Genova, R.C., Girma, B., Kissel, E.S., Levy, A.N., MacCracken, S., Mastrandrea, P.R., White, L.L. (Eds.). Cambridge University Press, Cambridge, United Kingdom and New York, NY, USA, 1132 pp.

Kamara, A., Friday, Y.E., David, C., Lucky, O.O., 2009. Planting date and cultivar effects on grain yield in dryland corn production. Agron. J. 101, 91-98.

Keating, B.A., Carberry, P.S., Hammer, G.L., Probert, M.E., Robertson, M.J., Holzworth, D., Huth, N.I., Hargreaves, J.N., Meinke, H., Hochman, Z., 2003. An overview of APSIM, a model designed for farming systems simulation. Eur. J. Agron. 18, 267-288

Lobell, D.B., Burke, M.B., Tebaldi, C., Mastrandrea, M.D., Falcon, W.P., Naylor, R.L., 2008. Prioritizing climate change adaptation needs for food security in 2030. Science 319, 607-610.

Muller, C.A., Bondeau A., Popp, K., Waha, M., Fader, 2010. Climate change impacts on agricultural yields. Background note to the World Development Report 2010. Potsdam Institute for Climate Impact Research, Potsdam.

Nakicenovic, N.J., Alcamo, G., Davis, B., de Vries, J., Fenhann, S., Gaffin, K., Gregory, A., Grubler, T.Y. Jung, T., Kram, 2000. Special report on emissions scenarios: a special report of Working Group III of the Intergovernmental Panel on Climate Change. Pacific Northwest National Laboratory, Richland, WA (US), Environmental Molecular Sciences Laboratory (US).

Niang, I., Ruppel, O.C., Abdrabo, M.A., Essel, A., Lennard, C., Padgham, J., Urquhart, P., 2014. Africa. In: Barros, V.R., et al. (Eds.), Climate Change 2014: impacts, adaptation, and vulnerability. Part B: regional aspects. Contribution of Working Group II to the Fifth Assessment Report of the Intergovernmental Panel on Climate Change. Cambridge University Press, Cambridge and New York, NY, pp. 1199-1265.

Parry, M.L., Rosenzweig, C., Iglesias, A., Livermore, M., Fischer, G., 2004. Effects of climate change on global food production under SRES emissions and socio-economic scenarios. Global Environ. Change 14, 53-67.

Piani, C., Weedon, G., Best, M., Gomes, S., Viterbo, P., Hagemann, S., Haerter, J., 2010. Statistical bias correction of global simulated daily precipitation and temperature for the application of hydrological models. J. Hydrol. 395, $199-215$.

Rosenzweig, C., Parry, M.L., 1994. Potential impact of climate-change on world food supply. Nature 367, 133-138.

Rosenzweig, C., Jones, J.W., Hatfield, J.L., Ruane, A.C., Boote, K.J., Thorburn, P., Antle J.M., Nelson, G.C., Porter, C., Janssen, S., Asseng, S., Basso, B., Ewert, F., Wallach, D., Baigorria, G., Winter, J.M., 2013. The agricultural model intercomparison and improvement project (AgMIP): protocols and pilot studies. Agric. Forest Meteorol. 170, 166-182.

Roudier, P., Sultan, B., Quirion, P., Berg, A., 2011. The impact of future climate change on West African crop yields: what does the recent literature say? Global Environ. Change 10, 1073-1083.

Salack, S., Traore, S., 2006. Impacts des changements climatiques sur la production du mil et du sorgho dans les sites pilotes du plateau central, de Tahoua et de Fakara. Internship report. AGRHYMET/CILSS, Niamey, Niger.

Sawadogo-Kaboré, S.M., Fosu, R., Tabo, R., Kanton, S., Buah, A., Bationo, S. Ouédraogo, S., Pale, M. Bonzi, K., Ouattara, 2009. Improving crop productivity and farmer income using fertilizer microdosing and the warrantage system in the Volta Basin. CGIAR Challenge Program on Water and Food:135.

Schlenker, W., Lobell, D.B., 2010. Robust negative impacts of climate change on African agriculture. Environ. Res. Lett. 5, 014010.

Serdeczny, O., Adams, S., Baarsch, F., Coumou, D., Robinson, A., Hare, W., Schaeffer, M., Perrette, M., Reinhardt, J., 2016. Climate change impacts in Sub-Saharan Africa: from physical changes to their social repercussions. Reg. Environ. Change, 1-16. 
Simelton, E., Quinn, C.H., Batisani, N., Dougill, A.J., Dyer, J.C., Fraser, E.D. Mkwambisi, D., Sallu, S., Stringer, L.C., 2013. Is rainfall really changing? Farmers' perceptions, meteorological data, and policy implications. Clim. Dev. 5, 123-138.

Sissoko, F., 2009. Analyse des flux d'eau dans les systèmes de culture sous couverture végétale en zone soudano sahelienne: Cas du coton semé après une culture de sorgho/brachiaria au sud du Mali. Centre international d'etudes supérieures en sciences agronomiques Montpellier. Montpellier SupAgro, p. 169.

Soumaré, M., Bazile, D., Vaksmann, M., Kouressy, M., Diallo, K., Hamala Diakité, C.H., 2004. Diversité agroécosystémique et devenir des céréales traditionnelles au sud du Mali. Cahiers Agricultures 17, 79-85.

Stott, P.A., Stone, D.A., Allen, M.R., 2004. Human contribution to the European heatwave of 2003. Nature 432, 610-614.

Stott, P.A., Jones, G.S., Christidis, N., Zwiers, F.W., Hegerl, G., Shiogama, H., 2011. Single-step attribution of increasing frequencies of very warm regional temperatures to human influence. Atmos. Sci. Lett. 12, 220-227.

Sultan, B., Roudier, P., Quirion, P., Alhassane, A., Muller, B., Dingkuhn, M., Ciais, P., Guimberteau, M., Traore, S., Baron, C., 2013. Assessing climate change impacts on sorghum and millet yields in the Sudanian and Sahelian savannas of West Africa. Environ. Res. Lett. 8, 014040.

Taylor, K.E., Stouffer, R.J., Meehl, G.A., 2012. An overview of CMIP5 and the experiment design. Bull. Am. Meteorol. Soc. 93, 485-498.

Taylor, S.H., Ripley, B.S., Martin, T., De-Wet, L.A., Woodward, F.I., Osborne, C.P. 2014. Physiological advantages of $C 4$ grasses in the field: a comparative experiment demonstrating the importance of drought. Global Change Biol. 20, 1992-2003.
Teng, J., Vaze, J., Chiew, F.H.S., Wang, B., Perraud, J.-M., 2012. Estimating the relative uncertainties sourced from GCMs and hydrological models in modeling climate change impact on runoff. J. Hydrometeorol. 13, 122-139.

Tingem, M., Rivington, M., 2009. Adaptation for crop agriculture to climate change in Cameroon: turning on the heat. Mitig. Adapt. Strateg. Global Change 14, $153-168$.

Tingem, M., Rivington, M., Bellocchi, G., 2009. Adaptation assessments for crop production in response to climate change in Cameroon. Agron. Sustain. Dev. 29, 247-256.

Traore, B., Corbeels, M., van Wijk, M.T., Rufino, M.C., Giller, K.E., 2013. Effects of climate variability and climate change on crop production in southern Mali. Eur. J. Agron. 49, 115-125.

Traore, B., van Wijk, M.T., Descheemaeker, K., Corbeels, M., Rufino, M.C., Giller, K.E., 2014. Evaluation of climate adaptation options for Sudano-Sahelian cropping systems. Field Crops Res. 156, 63-75.

Traore, B., 2014. Climate Change, Climate Variability and Adaptation Options in Smallholder Cropping Systems of the Sudano - Sahel Region in West Africa PhD. Wageningen University.

Trenberth, K.E., 2011. Changes in precipitation with climate change. Clim. Res. 47, 123.

Weedon, G., Gomes, S., Viterbo, P., Shuttleworth, W., Blyth, E., Österle, H., Adam, J., Bellouin, N., Boucher, O., Best, M., 2011. Creation of the WATCH forcing data and its use to assess global and regional reference crop evaporation over land during the twentieth century. J. Hydrometeorol. 12, 823-848.

Willmott, C.J., Ackleson, S.G., Davis, R.E., Feddema, J.J., Klink, K.M., Legates, D.R., O'Donnell, J., Rowe, C.M., 1985. Statistics for the evaluation and comparison of models. J. Geophys. Res. Oceans 1978-2012 (90), 8995-9005. 